\title{
UMA BREVE CRÍTICA DA TESE DO STF NA ADI 6421 À LUZ DA VISÃO SCHMITTIANA DE ADRIAN VERMEUELE E ERIC POSNER
}

\author{
Cláudio Ladeira de Oliveira, Lorenzo Furlan \\ Universidade Federal de Santa Catarina - UFSC. E-mail: claudioladeira@hotmail.com, furlan.elorenzo@gmail.com
}

\begin{abstract}
RESUMO
Este artigo servirá de espaço para uma crítica do Supremo Tribunal Federal, nos termos do voto do Ministro Luís Roberto Barroso, encampada pela maioria dos Ministros da Corte, na Ação Direta de Inconstitucionalidade (ADI) n. 6421, cujo pedido liminar foi julgado em 21 de maio de 2020, tendo por objeto a Medida Provisória 966/2020. Neste sentido, o artigo foi construído com maior atenção ao seu possível valor pragmático que propriamente por pretensões analíticas. O problema que se quer colocar é o seguinte: a tese do Ministro Barroso, especialmente o segundo ponto, pode contribuir para evitar as irracionalidades da ação dos administradores públicos no combate aos efeitos da pandemia? É possível indicar um caminho para responder esta questão que se coloca na posição crítica da visão segundo a qual os mecanismos de controle, especialmente, judicial, possuem eficácia para evitar irracionalidades administrativas, seja em tempos normais, seja principalmente, nas crises e emergências.
\end{abstract}

Palavras-chave: Ativismo; deferência judicial; black holes.

\section{A SHORT REVIEW OF THE ADI 6421 IN THE LIGHT OF VERMEULE AND POSNER SCHMITTIAN'S VIEW}

\begin{abstract}
This article will serve for pragmatic reasons, especially to critique of Justice Luís Roberto Barroso's thesis in Direct Action of Unconstitutionality (ADI) n. 6421, that was judged by the Federal Supreme Court on May 21, 2020, having as object the Provisional Order. Can put the problem in this question: can Minister Barroso's thesis, especially the second point, contribute to avoid the irrationalities of the action of public administrators in combating the effects of the pandemic? It is possible to answer this question from the critical position of the view according to which mechanisms of judicial review are effective in avoiding administrative irrationalities or akrasia, either in normal times, or mainly, in crises and emergencies, according to Vermeule and Posner schmittian view.

Keywords: judicial review; schmittian view; black holes.
\end{abstract}

\section{INTRODUÇÃO}

Este artigo servirá de espaço para uma crítica da tese do Supremo Tribunal Federal, nos termos do voto do Ministro Luís Roberto Barroso na Ação Direta de Inconstitucionalidade (ADI) n. 6421, encampada pela maioria da Corte, cujo pedido liminar foi julgado pelo órgão em 21 de maio de 2020, tendo por objeto a Medida Provisória (MP) 966/20. Neste sentido, o artigo foi construído com maior atenção ao seu possível valor pragmático que propriamente por pretensões analíticas. Um dos atos normativos do Presidente da República mais atacados por meio dos mecanismos de controle de constitucionalidade durante esta pandemia foi a Medida Provisória n. 966 de 13 de maio de 2020, que reproduziu preceitos da Lei de Introdução do Direito brasileiro para tratar do regime de responsabilizações dos agentes públicos em áreas como a saúde e a economia, concernente às ações (comissiva ou omissivamente) com dolo ou "erro grosseiro", tomadas para o enfrentamento 
da pandemia. Os partidos articularam algumas ações diretas de inconstitucionalidade para impugnar a medida adotada pelo Executivo, sendo uma delas a ação que procurar-se-á analisar no presente trabalho.

A ação é paradigma para a crítica, uma vez que foi decidida por um dos principais defensores do ativismo judicial no Brasil. No julgamento provisório do feito, a tese do Ministro Relator, Luís Roberto Barroso, seguida pela maioria dos Ministros, segundo a qual não pode se encaixar no conceito de "erro grosseiro" as ações dos agentes públicos que forem tomadas i) contrariamente as recomendações científicas dadas por autoridades reconhecidas como tais; ii) desrespeitar os princípios da prevenção e precaução.

O problema que se quer colocar é o seguinte: a tese do Ministro Barroso, especialmente o segundo ponto, pode contribuir para evitar as irracionalidades da ação dos administradores públicos no combate aos efeitos da pandemia? É possível indicar um caminho para responder esta questão que se coloca na posição crítica da visão segundo a qual os mecanismos de controle, notadamente judicial, possuem eficácia para evitar irracionalidades administrativas, seja em tempos normais, seja principalmente, nas crises e emergências.

A crítica terá como base teórica a visão teórica defendida pelo professor Adrian Vermeule e pelo professor Eric Posner, identificada por eles como a visão schmittiana. Com isso, para demonstrar o acerto da crítica, a partir desta visão, no caso, utilizar-se-á o método indutivo, através do qual percorrer-se-á o seguinte caminho: 1) uma revisão bibliográfica que formará a base teórica, de modo que apresentarei conceitos centrais como ativismo, deferência e os principais expedientes teóricos com o s quais analisarei o caso, principalmente os conceito de black holes e grey holes; 2) descrição da tese do Relator e a crítica de acordo com essa visão teórica e pragmática e apresentarei alguns resultados parciais.

\section{JURISDIÇÃO CONSTITUCIONAL ENTRE ATIVISMO E DEFERÊNCIA}

Nesta seção procurarei distinguir duas maneiras de encarar a atividade de interpretação jurídico-constitucional. Como o artigo tem por objeto a crítica da ADI 6421/6427, e, portanto, do próprio controle de constitucionalidade de um ato normativo do Executivo, essa relação será feita tendo em vista as implicações para o campo do Direito Administrativo.

\subsection{Ativismo judicial no direito administrativo}

Tanto o pós-positivismo como o neoconstitucionalismo são palavras ambíguas e geram mais confusão que ajudam a esclarecer. Ambos os termos se referem à cultura jurídica predominante na segunda metade do século $X X$, sendo que $O$ segundo foi cunhado originariamente por juristas espanhóis e italianos, tendo por referência a reconfiguração do direito constitucional após o ocaso dos regimes totalitários. No Brasil, com o neoconstitucionalismo misturaram-se aspectos da Escola da Jurisprudência da Valoração, do moralismo jurídico em geral, seja pela teoria dworkiana, seja pela teoria da argumentação alexyana. Vale lembrar, a Jurisprudência da Valoração foi a "Escola" hegemônica no contexto fundacional da Alemanha pós-nazista e sua ideia central é a ruptura com o postulado da separação entre direito e moral, segundo o juízo de que a atividade de conhecimento do direito envolve empreender uma sorte de "valoração adicional", na esteira da crítica dos elementos centrais do positivismo jurídico em sentido estrito. (LARENZ, 2019; STRECK; TRINDADE, 2012, p. 60-61)

Luís Roberto Barroso é um dos principais expoentes do neoconstitucionalismo. $\mathrm{O}$ termo é utilizado por ele para identificar o que o autor sugere ser o conjunto de modificações sobre o direito constitucional, à medida que a doutrina jurídica positivista sofreu profundas críticas em relação a seus aspectos fundamentais, como a noção de coação, norma, ordenamento jurídico e a questão da interpretação judicial como uma atividade de subsunção. Aquela refutação à separação entre direito e moral é feita por Barroso com a tese da "leitura moral da Constituição" de Ronald Dworkin, cuja defesa da interpretação constitucional pautada em critérios de justiça substantiva, notadamente os princípios, é reproduzida pelo constitucionalista brasileiro de modo a estilizar uma sorte de razão prática na argumentação jurídica. (BARROSO, 2017, p. 53-56) Segundo este paradigma, o próprio conceito de Constituição foi ressignificado para compreender a ideia formulada na jurisprudência do tribunal constitucional alemão, segundo a qual a ordem constitucional seria uma espécie de ordem objetiva de valores. (BARROSO, 2012, p. 35; BÖCKENFÖRD, 2017, 165-168; LARENZ, 2019) 
Essa forma de compreender a interpretação jurídica, em geral, e a interpretação constitucional, particularmente, segundo a qual os juízes devem tomar decisões pautados em critérios morais externos ao direito positivo pode ser vista como uma forma de ativismo judicial. Segundo Elival Ramos o ativismo judicial significa a prática da interpretação-aplicação do direito pelo qual os juízes ultrapassam o núcleo essencial das funções a eles incumbidas. (RAMOS, 2015)

Esse ativismo judicial defendido por Barroso precisa também partilhar uma visão realista e descritiva da atividade política no Legislativo, enquanto o Judiciário é visto de modo idealizado. A política estaria tomada de articulações e barganhas, sendo uma atividade muito mais passível de ser capturada pela "corrupção", enquanto a interpretação constitucional feita pela Corte seria uma atividade qualitativamente superior, porque, entre outros argumentos, juízes teriam sido escolhidos através do concurso público. É importante dizer que a interpretação constitucional é feita também no processo legislativo e que existem deputados comprometidos com os valores democráticos, da mesma forma que existem juízes descomprometidos com tais valores.

Seja como for, tal visão atravessa vários campos do direito, no processo sugerido como constitucionalização do direito, segundo o qual o conteúdo axiológico da Constituição se irradia por todo ordenamento jurídico. No Direito Administrativo, o professor Juarez Freitas sugeriu uma visão segundo a qual a legislação produzida pelo Executivo, seja em relação a decisões normativas ordinárias, como um concurso público, seja em relação a políticas públicas, igualmente, são atacadas como fonte potencial de akrasia e desvios cognitivos que imprimiriam a necessidade e legitimidade do controle substancial e sistemático. Para justificar esta argumentação em torno da tese da ampla "sindicabilidade" dos atos administrativos pelo Judiciário, o autor toma emprestado o mapa dos vieses da sociologia e projeta qualidades negativas sobre a tomada de decisão dos administradores. Com efeito, a discricionariedade impulsivista (sic) é uma ação desprovida de senso cognitivo de controle, por se valer da lei do menor esforço, de modo que "[...] confunde facilidade cognitiva com verdade, abusa das heurísticas e simplifica demais, especialmente ao substituir questões difíceis por fáceis, além de inventar causas." (FREITAS, 2015, p. 338)

Para essa ampla "sindicabilidade" fazer sentido, pressupõe-se a ruptura com a tradição teórica positivista e formalista que, no âmbito do direito administrativo, postula a dualidade rígida entre atos administrativos discricionários e vinculados. A teoria do direito formalista e positivista conceitua o ato administrativo como manifestação da vontade da administração pública, por meio de agentes públicos, no exercício das suas competências e responsabilidades públicas, fundamentados na legalidade, e cujas características são a particularidade e para criar uma situação legal nova. Para o pensamento positivista, na dualidade clássica, todo ato administrativo precisa cumprir os requisitos de validade, a competência, a finalidade pública, a forma prescrita em lei, a motivação e o objeto. Mas, como os atos administrativos se subdividem em dois tipos, os vinculados e os discricionários, e como somente os elementos ou requisitos vinculados do ato geralmente (compreendidos como a competência, finalidade e forma) comportariam sindicância, deixa-se o motivo e objeto como elementos discricionários e, portanto, fora da possibilidade de controle. Ao passo que os atos vinculados seriam aqueles atos administrativos aos quais o legislador especificou os requisitos, de modo que ao agente público é reduzida a margem para a discrição, atos discricionários seriam aqueles cuja motivação e objeto permitem maior margem de discrição para o agente público, que preenchera seus espaços vazios através de juízos de conveniência e oportunidade. Os juristas do direito administrativo formularam diversas teorias: (a) as teorias do desvio de finalidade; (b) as teorias dos elementos ou motivos determinantes do ato; (c) as teorias dos conceitos jurídicos indeterminados; (d) as teorias dos controles; até chegar ao momento contemporâneo, com (e) as teorias dos graus de vinculação a escala a priori de juridicidade. À medida que mais se aproximou da ideia de juridicidade, mais reduzida ficou a discricionariedade do ato política da Administração Pública, de maneira que, inclusive, fala-se em redução da discricionariedade a zero. Justamente, o neoconstitucionalismo, e constitucionalização do direito administrativo, apareceu como fenômeno que possibilitou a superação das "anomalias" do paradigma tradicional, positivista. E como uma opção ao 
déficit teórico do pensamento jurídico positivista, a constitucionalização do direito administrativo provocou a vinculação da Administração Pública direta e imediatamente à Constituição e a adoção da teoria da vinculação aos graus de juridicidade. (BINEMBOJM, 2008)

Se a discricionariedade é reduzida a zero, é claro que não existe mais separação entre atos administrativos vinculados e discricionários. $\mathrm{O}$ ato administrativo vinculado "[...] como aquele em que o agente, no âmbito da Administração lato sensu, deixa de ter qualquer liberdade, isto é, resta jungido a cumprir os comandos legais" (FREITAS, 2015, p. 334), e não existe mais, porque não pode ser reduzido ao princípio da legalidade estrita, como se o administrador agisse automaticamente quando um ato encontra seus elementos constitutivos na legislação, a despeito do dever de fundamentação e, mesmo, reflexão, sobre as consequências do ato, à luz da rede principiológica da Constituição. Da mesma forma "[...] não existe discricionariedade administrativa total, pois os elementos discricionários (motivo e objeto) precisam guardar vinculação, antes de tudo, com o sistema de princípios e direitos fundamentais." (FREITAS, 2015, p. 332)

Freitas refere-se ao controle das políticas públicas com base no imperativo da proporcionalidade como um teste. Para isso, alarga o conceito de políticas públicas, para além da significação de ações de governo, e passa a compreendê-las como "prioridades constitucionais vinculantes", isto é, decisões fundamentais, adotadas pelo Estado e cristalizadas no corpo de uma Constituição, que se voltam ao bem-estar intergeracional, a implementação de programas eficientes e justificados com base numa análise prospectiva geracional. Esse exercício proporcional do controle leva Freitas a sustentar a tese de que o Judiciário se comporte como um "administrador negativo".

Mas, como poderia de fato exercer o papel de "administrador negativo", tal como o seu co-irmão kelseniano, o "legislador negativo", se terá a missão difícil de compreender e prezar pelo cumprimento de complexas "prioridades constitucionais vinculantes"? Certamente, é difícil que a atividade judicial que controla e julga a inconstitucionalidade de uma norma do Executivo, colocando, ainda que de forma singela, outra variação exegética no lugar da norma impugnada, seja considerada como mero subproduto deste tal "administrador negativo".
De um lado, é interessante mencionar que essas teses neoconstitucionalistas se baseiam muito em Dworkin. Só que é preciso registrar que Dworkin não trabalhava suas teses, como a da resposta correta, em bases de discricionariedade (forte ou fraca), uma vez que tal conceito pertenceria a linguagem do positivismo jurídico. É mais correto supor que Dworkin procurava mitigar os poderes decisórios do julgador, "amarrando-lhe" os vínculos da história institucional da comunidade. Certamente, sua pretensão de correção moral envolve adaptar o significado das normas e, mesmo, contestar sua validade, à melhor luz moral delas em dado contexto; mas isso não fazia do filósofo um defensor de uma "cruzada moral" dos juízes. (DWORKIN, 2002; 2006; 2014)

De outro lado, as teses do neoconstitucionalismo muito se aproximam da teoria alemã dos direitos fundamentais do PósSegunda Guerra, com atenção às formulações do filósofo Robert Alexy, mas que, em certos pontos, podem também ser aceitas por Dworkin. Em bases de uma filosofia analítica universalizante, Alexy (2014) afirma que as normas de direitos fundamentais possuem estrutura fundamental de normas-princípios, isto é, consistem em disposições normativas com maior grau de abstração - no que Dworkin também aceitava (DWORKIN, 2002). Alexy sugere a proposição segundo a qual a estrutura das normas de direitos fundamentais é de normas-princípios. Essa concepção foi aceita também pelo Tribunal Constitucional Alemão, que compreendeu a ordem constitucional como uma ordem objetiva de valores, positivados via direitos, dentro do paradigma normativo denominado Jurisprudência da Valoração. (BÖCKENFÖRD, 2017; LARENZ, 2019) Como Alexy as define, as normas de caráter principiológico possuem estrutura normativa prima facie, de modo que se realizam à medida do possível, diante das possibilidades fáticas e jurídicas, ao passo que as normas-regra possuem uma estrutura definitiva, cuja aplicação se dá de forma subsuntiva. Com efeito, quando um ato estatal se direcionar para expandir um direito, necessariamente, provocará a restrição noutro. Suponha um exemplo. A autoridade política do Chefe do Executivo local escolhe investir recursos para a implementação de um posto de saúde em um bairro que necessitava daquela política. Essa escolha naturalmente encontra fundamento na juridicidade do direito fundamental a saúde, uma norma-princípio. 
Suponha, todavia, que no mesmo período daquela escolha, outro bairro da cidade necessitava da implementação de uma creche. Essa demanda encontra respaldo no direito fundamental a educação. Logo, há um conflito normativo entre direitos fundamentais: a saúde, que sustenta a medida política adotada, e a educação, que sustenta a pretensão não adotada. Uma vez instaurado o controle sobre a decisão política do Chefe do Executivo, sobretudo judicial, o imperativo da proporcionalidade é estrutura de raciocínio consistente em avaliar a relação entre os meios e os fins, isto é, entre a decisão política adotada e as finalidades que busca fomentar. Essa estrutura de pensamento encerra através da lei da ponderação, que cria uma relação de precedência entre os princípios. $E$ é por meio dela que se resolveriam os conflitos entre os direitos fundamentais. (ALEXY, 2012, p. 39 e 85$)$.

\subsection{Deferência judicial aos atos administrativos}

Em oposição ao ativismo, um dos fundamentos do "programa" da moderação judicial é a teoria da deferência (DWORKIN, 2002), muito aplicada no âmbito do controle judicial sobre $o$ ato administrativo, ainda mais com a Doutrina Chevron (SUNSTEIN; VERMEULE, 2002), sobretudo, por sobre aquilo que a doutrina brasileira convencionou chamar, como visto no item anterior, ato administrativo discricionário.

Neste sentido, um modelo deferente de compreensão e aplicação do direito, em geral, e do Direito Administrativo e Constitucional, em particular, com raízes em Schmitt (1996; 2007), é oferecido pelo professor de Harvard, Adrian Vermeule. Vermeule, junto com Eric Posner, primeiramente em artigo, e, posteriormente, em livro, defendem o que denominam de visão schmittiana (schmittian's view), segundo a qual a ampla deferência ao Executivo não só é a melhor saída como também a única saída viável em tempos de crises ou emergências, e, mesmo, que o próprio direito deliberadamente, por meio de seus atores fundamentais, decidiu que a deferência é a melhor opção. (POSNER; VERMUELE, 2008; 2010)

Dworkin procurou contestar essa visão em favor da atitude da deferência, mormente, derivando a legitimidade dos mecanismos do controle judicial do conceito de democracia constitucional e, portanto, do pressuposto do igual tratamento e respeito aos cidadãos. Ele realmente acreditou que, mormente em se tratando dos resultados, a existência e a prática dos mecanismos de controle judicial estariam justificadas conforme a democracia. (DWORKIN, 2002; 2006; 2014)

Mas, indo além de Dworkin, a sua crença no ativismo judicial, sobremaneira, em crises e emergências, deve ser contestada com uma simples questão: como poderia uma jurisdição constitucional, especialmente uma Corte composta por poucos juízes não eleitos e não especializados em política, com capacidade de ação extremamente limitada por fatores de ordem institucional, social, política, econômica e até cognitivos, atuar na linha de frente das crises e emergências? Bom, as razões que mostram os problemas de ação coletiva das Cortes, mas igualmente do Legislativo, são retiradas dos contextos de normalidade institucional e social, embora sejam muito mais evidentes em contextos de crises e emergências.

\subsubsection{Problemas da ação coletiva do Legislativo e das Cortes}

Mesmo em contextos de normalidade, geralmente as razões atreladas a deferência ampla ao Executivo envolvem a comparação de fatores institucionais e políticos que afetam as capacidades dos atores institucionais relevantes, é dizer, que atingem negativamente as ações do Legislativo, por meio dos representantes políticos, e das Cortes, na ação dos juízes. Algumas razões concorrem para provar a afirmação, segundo a qual o Executivo possui vantagens no agir em relação as outras agências. As desvantagens institucionais e políticas da ação dos outros Poderes deveriam incentivar uma deferência, sobretudo, em temas delicados e complexos, como segurança e saúde públicas. Três problemas geralmente concorrem para dificultar a tomada de decisões por parte das agências legislativas e das Cortes: 1ㅇ) assimetrias de informação; 2ㅇ) os problemas de ação coletiva; 3) a dispersão ou, como é costume midiático chamar, a fragmentação partidária. A tomada de decisões, mesmo em tempos normais, exige certa expertise, ainda mais, quando estamos falando do controle do Executivo que possui estrutura de pessoal e recursos para obter informações privilegiadas para agir sob as incertezas, enquanto os parlamentos e as Cortes enfrentam sérios problemas relacionados à dificuldade de obter esses dados. (POSNER; 
VERMEULE, 2010, p. 4, 24 e 32-33; VERMEULE, 2016, p. 3-4 e 24)

As instituições representativas até podem possuir comitês próprios para produzir a expertise e informação necessárias ao agir, isso em várias áreas, contudo, essas estruturas têm pouco ou nenhum controle real em relação a assuntos como a política externa e a segurança nacional. (POSNER; VERMEULE, 2010, p. 26)

Deveras, o Congresso age institucionalmente por meio dos seus diversos membros, os quais devem aderir a procedimentos deliberativos, alguns mais outros menos complexos, mas que, de uma forma ou de outra, atrasam a ação parlamentar em relação à ação executiva. Por isso, aos problemas de ação coletiva, o ponto crucial envolve o fato de que "[...] o Executivo pode agir com muito mais unidade, força e 'despacho' que o Congresso, o qual é cronicamente dificultado pela necessidade do debate e consenso entre um número amplo." (POSNER; VERMEULE, 2010, p. 27) A própria formação partidária do Congresso pode atingir em cheio a capacidade de ação em tempos de crises e o ideal da separação dos poderes, na medida em que, se os mesmos partidos (ou se a coligação partidária mais ampla, acrescento) estiverem controlando ambas as agências, então a supervisão real do Executivo raramente ocorrerá. De modo que a maior ou menor intensidade e força da supervisão congressual depende da composição partidária do legislativo. ${ }^{1}$ (POSNER; VERMEULE, 2010, p. 28)

De outro lado, em relação aos juízes da Suprema Corte, os mesmos problemas estão presentes, de forma ainda pior, pois, além de sofrerem de problemas estruturais, que envolvem a geração da informação necessária para agir sob condições de incerteza genuína, e não possuírem os recursos necessários para agir na linha de frente desses contextos, as instituições judiciais em geral não são representativas, particularmente a jurisdição constitucional, apresentando problemas sérios de legitimidade democrática.

\section{Ao fim e ao cabo}

$$
\begin{aligned}
& \text { Juízes deferem porque } \\
& \text { eles pensam que o } \\
& \text { executivo tem melhor }
\end{aligned}
$$

\footnotetext{
${ }^{1}$ Interessante notar que, se os legalistas liberais advogam que a supervisão congressual é mais necessária em momentos de unidade governamental, quando o presidente controla o Congresso, é justo nesses períodos que é menos provável ainda que os membros do legislativo se prestem ao papel ativo de fiscalizar e frear o Executivo.
}

informação que eles, e também porque pensam que essa assimetria de informação ou "gap" aumenta ao passo que a complexidade da taxa de mudanças subjacente às questões políticas aumenta; porque (mesmo se os juízes sejam céticos em relação a informação do executivo realmente é superior, ou se eles são céticos sobre as motivações do executivo) porque eles estão cientes da sua própria falibilidade e temem os danos à segurança nacional ou ao bem estar econômico que pode crescer se eles superarem erroneamente as políticas do executivo; e porque eles temem o atraso que pode surgir do poder judicial de revisão, e isso pode ser especialmente danoso quando $\mathrm{o}$ tempo é essencial. (POSNER; VERMEULE, 2010, p. 106).

Como o nome indica, essa visão em prol da deferência encontra lastro na teoria e filosofia do direito de Carl Schmitt. (SCHMITT, 1996; 2007) Claramente em uma linha schmittiana, se pensarmos nos modelos de jurisdição constitucional com poder de revisão dos atos dos poderes eleitos, o principal custo é o atraso: quando se submete uma ação política do Executivo ao escrutínio judicial espera-se um tempo que talvez seja fatal nas crises, ainda mais se a fundamentação da decisão judicial for levada a sério. E é extremamente custoso implementar formas de controlar o abuso do poder por agentes público como é extremamente custoso para juízes produzirem decisões justificando adequadamente a intervenção no campo de competências do Executivo. $O$ próprio aparato destinado a essa tarefa é composto por agentes públicos, que podem, como qualquer agente público, abusar do poder ao qual estão investidos. (POSNER; VERMEULE, 2010, p. 58)

Ainda assim, nos contextos de normalidade é possível acompanhar um percurso histórico no sentido de fixar barreiras a partir das estruturas do Estado de Direito à ação do 
Executivo, até mesmo linhas imaginárias de redução da discricionaridade administrativa a zero, a partir da vinculação a normas de caráter principiológico do Estado de Direito, e que, de fato, são sempre ultrapassadas pelo Executivo, contando com a própria cooperação dos juízes e legisladores, que deixam buracos negros e/ou cinzentos para o Estado administrativo. Essas formas legais de controle e restrição dos agentes públicos - derivadas da separação dos poderes, como as legislaturas e o poder de revisão judicial, criadas sob a lógica da precaução contra o abuso de poder (VERMEULE, 2014, p. 50-56) -, não são suficientemente firmes para restringir 0 Executivo ou, ainda, podem se encontrar em colapso, porque o próprio direito público teria concluído que a abnegação do seu império em favor do Estado administrativo é a melhor saída. (VERMEULE, 2016, p. 1-2 e 5)

\subsubsection{Crises, emergências: explosão das black e grey holes}

Em contextos de crises e emergências muitas decisões não são tomadas dentro do direito ou da legalidade. Ambos são instrumentalizados pelas forças políticas dominantes na comunidade. A autoridade soberana capaz de decidir sobre a emergência pode receber legitimidade em fundamentos fora e além do (Estado de) direito. A legalidade é abdicada à passagem do aparato burocrático do Estado Administrativo, afinal, crises e emergências exigem do poder público a tomada de medidas extraordinárias, inclusive, envolvendo restrições a direitos, e as quais só o Executivo é capaz de tomar. (DYZENHAUS, 2006, p. 36)

O problema da legitimidade do controle de constitucionalidade, nas crises e emergências, envolve, também, a questão da preservação da ordem constitucional e democrática, ou seja, uma questão de eficácia desses mecanismos legais. E se insere dentro de um problema ainda maior, como colocou David Dyzenhaus. Carl Schmitt lançou um desafio difícil aos teóricos liberais: questionar se o Estado de Direito é realmente uma opção para as sociedades democráticas em contextos de crises e emergências. (SCHMITT, 2007). Afinal, as crises e emergências deflagram situações complexas em que o próprio direito deixa espaços para o Executivo agir sem se vincular aos princípios e exigências do Estado de direito, e, também, situações em que a revisão judicial da ação executiva é excluída. (DYZENHAUS, 2006, p. 1-4 e 34).

Diante desse desafio, o principal objetivo de Dyzenhaus foi demonstrar que a ideia de Estado de Direito e seus consectários, principalmente o controle de constitucionalidade, tem lugar central durante as emergências ou crises, especialmente, tentar provar a afirmação segundo a qual os juízes possuem o dever moral de proteger o Estado de direito contra as arbitrariedades do Estado, sobretudo quando as legislaturas e o Executivo se retiram da defesa coordenada desse projeto, a exemplo de quando autorizam os buracos negros e cinzas. Dyzenhaus sabe que é difícil para juízes atuarem decisivamente e responder às crises e emergências, por isso, reconhece que certa deferência deve ser prestada. Mas ainda o controle de constitucionalidade é mecanismo central do Estado de direito, pelo qual os juízes atuam para colocar limites a ação dos outros poderes, alertando para o possível descumprimento daqueles vínculos com o Estado de direito e para exigir o comprometimento dos atores políticos. No seu modelo, importante salientar, não se pressupõe os Poderes competindo pela supremacia, mas, antes, o comprometimento recíproco com ideal normativo do projeto do Estado de Direito. Disso deriva compreender a legitimidade dos juízes para determinar o conteúdo do direito em concordância com o ideal dever de proteger o Estado de direito. (DYZENHAUS, 2006, p. 4-6, 8-9 e 38-39).

O conceito de black holes refere-se ao espaço deixado pelo próprio direito para o Executivo agir sem se vincular aos princípios e exigências do Estado de direito, enquanto o conceito de grey holes envolve as situações em que a revisão judicial da ação executiva é excluída. (DYZENHAUS, 2006, p. 2-3)

Apesar de os black holes $\mathrm{e}$, principalmente, grey holes existirem de fato, legisladores e juízes devem aderir a uma concepção substancial de Estado de direito, segundo a qual estão comprometidos com o dever constitucional de defender o Estado de direito nessas situações, recorrendo a serviços de legitimidade moral. (DYZENHAUS, 2006, p. 34).

Ao contrário de Dyzenhaus, Posner e Vermeule argumentam que, se em momentos de crise é inevitável que apareçam essas situações de buraco negro - pois ninguém consegue prever minuciosamente como e quando a externalidade 
pode ocorrer, nem quais efeitos produzirá em curto, médio e longo prazo sobre a economia e o bem estar social -, mesmo em situações normais não há como superá-las, pois essas "brechas" fazem parte do Estado Administrativo, sendo deliberadamente deixadas à discrição do Executivo pelos atores políticos relevantes, em virtude da necessidade e da própria intensidade das mudanças na política e na economia. (POSNER; VERMEULE, 2010 p. 92-93) Vale ressaltar, os próprios legisladores entendem que, em certos pontos e em certas áreas, é inevitável deixar buracos negros, até para que os administradores possam ter uma margem de ajuste da ação à mudança nas condições socioeconômicas e políticas. (POSNER; VERMEULE, 2010, p. 104).

Vale pontuar quem mesmo em contextos de normalidade, talvez valha a pena, para a teoria da decisão/interpretação constitucional e administrativa, falar na existência de tipos decisórios com carga de arbitrariedade, no sentido da teoria da decisão, mas sem que isso signifique lesão a direitos. Vermeule identificou que existem decisões racionalmente arbitrárias do Executivo, as quais são constitutivas do próprio Estado Administrativo. Em condições de incerteza genuína, isto é, sob condições em que se sabe que certos resultados podem ocorrer, só não se sabe quais são as probabilidades certeiras, as decisões do Executivo podem ser consideradas arbitrárias, mas não necessariamente no sentido de mal motivadas, simplesmente no sentido de que precisam dar um "salto no escuro"; e são racionais porque os administradores não o fazem do nada, mas tomam essas decisões com informações, instrução técnica, recursos e tempo - elementos necessários para procurar a ação mais adequada do ponto de vista do custobenefício. (VERMEULE, 2016)

\section{CRÍTICA DA TESE DO RELATOR NA ADI 6241}

A MP 966 foi editada pelo Presidente da República (BRASIL, 2020.b), em meio a um processo de baixa da sua credibilidade $\mathrm{e}$ popularidade, associado ao modo como tem conduzido o Estado administrativo durante a pandemia. O principal significante vazio da campanha política de Jair Bolsonaro foi a luta contra a "corrupção" como o bem maior. Depois de meses de governo, em virtude de fatos, como os conflitos com o ex-Ministro da Justiça e ex-juiz da Lava Jato, Sérgio Moro, o Presidente parece ter a reputação e o ethos de credibilidade e integridade afetados para pior.

No contexto da pandemia, com tal baixa da popularidade e credibilidade, o Presidente da República tem sofrido o revide institucional, dos Ministros da Corte. A MP 966 teve por objeto disciplinar o sistema de responsabilizações da Administração Pública pelas medidas adotadas na pandemia, em áreas delicadas, como saúde e economia, de modo que só poder-se-ia imputar sanções e responsabilizações aos agentes quando não incidissem em "erro grosseiro". 0 art. 1 da MP 966 colocou a regra da responsabilização somente quando os agentes agem com dolo ou erro grosseiro, seja no enfrentamento da emergência, seja no combate dos efeitos da pandemia. (BRASIL, 2020.b)

O Partido autor da ação é a Rede Sustentabilidade e a inicial sintetiza dois argumentos centrais: primeiro, que a Constituição não previu uma responsabilização subjetiva para esses casos de danos causados pela Administração Pública, pelo contrário, a responsabilidade seria objetiva; depois, expressões indeterminadas, notadamente, o conceito de "erros grosseiros", como envolvem alta carga de valoração normativa, consequentemente, fortalecem os obstáculos para a fiscalização das ações do Executivo durante a pandemia. (BRASIL, 2020.c)

\subsection{A tese do Relator}

A ADI 6421 foi protocolada em 15 de maio de 2020 pelo partido político Rede Sustentabilidade e teve por objeto a MP 966/2020 (BRASIL, 2020.b; BRASIL, 2020.c), editada pelo Presidente para disciplinar o regime de responsabilizações dos agentes públicos pelos erros cometidos em áreas como a saúde e a economia durante a pandemia no Brasil, especialmente em relação as ações (comissivas ou omissivas) com dolo ou "erro grosseiro". O autor da ação pediu, principalmente, que fosse deferida medida cautelar com efeitos retroativos para sustar a eficácia do ato, e das outras disposições normativa conexas, ou, subsidiariamente, para sustar a eficácia somente da MP, até que o Congresso Nacional analise a medida; ou, ainda, para aplicar a Interpretação conforme a Constituição (ICC) a fim de excluir a variante interpretativa às situações que envolvam danos ao erário, tanto em relação à MP como em virtude da disposição da Lei de Introdução às Normas do Direito Brasileiro. 
Esse último pedido foi encampado e, por meio da técnica da Interpretação conforme a Constituição (ICC), o Relator afirmou a seguinte tese: (1) Configura "erro grosseiro" o ato administrativo que não seguir recomendações científicas das autoridades reconhecidas e violar os princípios da precaução e prevenção; (2) As autoridades competentes para decidir devem exigir que as opiniões técnicas em que se fundamentará a decisão tratem explicitamente de a) normas e critérios científicos e técnicos da matéria, como aquelas recomendações indicadas acima; e b) os princípios mencionados, sob pena de se tornarem corresponsáveis pelas violações a direitos que eventualmente ocorrerem. O Ministro utilizou mecanismo da ICC para retirar do âmbito da MP os atos ilícitos e de improbidade, já regulamentados pela legislação administrativa sancionatória. Isso tudo tendo em vista que o próprio legislador constitucional promulgou a Lei Federal no 13.979/2020, na qual expediu comandos normativos para o combate da pandemia no país. (BRASIL, 2020.a) Lembrando que, até então, a MP 966 trazia a seguinte definição de "erro grosseiro", como aquele "[...] manifesto, evidente e inescusável [...] com culpa grave, [...] com elevado grau de negligência, imprudência ou imperícia." (BRASIL, 2020.b)

Um dos fundamentos da ICC é a ideia da presunção de constitucionalidade dos atos normativos, derivada das normas constitutivas do sistema representativo constitucional, como a regra das eleições, a igualdade, a participação e a representação política, bem como derivada da partilha das funções de Estado, de forma que consiste em fator de limitação da atuação judicial. A presunção estabelece como que a regra é a constitucionalidade; a exceção é a inconstitucionalidade. Portanto, se existir interpretação alternativa possível para afirmar a conformidade da norma com a Constituição. 0 problema é que essa técnica é uma forma aparentemente mais suave de controle, pois, sob o eufemismo da "preservação do ato normativo", serve como mais uma técnica jurídica para expandir a autoridade política do Judiciário sobre o legislador constitucional (Legislativo e Executivo).

O Relator acertou quando previu que as ações executivas devem observar opiniões e critérios técnicos e embasados na ciência. Certamente, $\mathrm{o}$ fato de que o Presidente repetidamente se manifestou em público com atos de fala negligentes com relação à pandemia, e interpelativos da flexibilização do isolamento sob quaisquer circunstâncias, certamente contribui para se criar uma crença negativa sobre a ação executiva. Até porque a decisão não determina nada além daquilo que a estrutura do Poder Executivo já comporta. Isso porque o Executivo é o único poder realmente capaz de produzir informações sobre áreas delicadas como a saúde e a economia, já que conta com uma burocracia ampla e repleta de agentes especializados nessas áreas.

\subsection{Mais um buraco negro do Judiciário: uma breve crítica}

O problema está mesmo na segunda parte da tese do Ministro. A tese do Ministro Barroso pode até ser considerada adequada para atingir a finalidade perseguida, mas produz efeitos perversos, especialmente o segundo ponto, pois, ao "tapar" um buraco negro/cinzento da ação do Executivo, abriu outro que favoreceu o Judiciário. Conforme o próprio raciocínio da precaução do Relator, o risco alvo da sua tese - evitar o abuso do poder Executivo pela não imputação de responsabilidade aos agentes públicos -, possui um risco compensatório de na margem permitir que o Judiciário delibere sobre as decisões racionalmente arbitrárias do Executivo (VERMEULE, 2014, p. 64-72) e pratique, ele mesmo, tais decisões. Em outros termos, quando buscou "tapar" um buraco, criou outro, só que para o próprio Judiciário.

A tese foi construída explicitamente com bases nessa lógica da precaução (VERMEULE, 2014, p. 27-51) que, como tal, traz em si uma lógica reversa e perversa, pela qual os riscos compensatórios na margem exacerbam o próprio risco alvo da decisão. A ideia é que toda lógica da precaução traz inserida em si a lógica reversa; se uma decisão em sede do poder de revisão judicial procura evitar danos gerados pelas ações do Executivo sem a devida precaução, ela também assume que pode potencializar outros riscos, como o de o próprio Poder Judiciário interpretar equivocadamente quando o ato do administrador não se deu com respaldo técnico e científico e, até mesmo, o abuso do controle judicial da Administração Pública. Afinal, o próprio aparato destinado a tarefa de avaliar quando o ato é ou não "erro grosseiro", o Judiciário, é composto por agentes públicos que podem muito bem errar na sua 
avaliação e abusar do poder ao qual estão investidos. (VERMEULE, 2016, p. 58; VERMEULE, 2014, p. 64-72)

O Ministro complementou o possível buraco negro da Medida Provisória com outro, talvez mais problemático ainda, posto que 0 destinatário principal não é mais uma instituição controlada pelo "povo" e pela opinião pública democrática, isto é, o Executivo; agora, quem tem e teve um buraco negro para agir foram os próprios juízes da Corte. Afinal, o Ministro limitou o alcance de um conceito indeterminado da MP o "erro grosseiro" - por outro conceito indeterminado - o "princípio da precaução". Sendo que a determinação do significado desse princípio é tão ou mais problemática quando os juízes se avocam dessa interpretação que quando os próprios administradores a fazem.

Isso porque, por mais seja defendida uma espécie de legitimação discursiva da Corte para desempenhar o papel da "representação argumentativa da sociedade" - como Robert Alexy propôs e Barroso (2017, p. 56) defendeu -, e por mais seja sustentado a necessidade do controle e a capacidade cognitiva e epistemológica dos juízes apresentarem razões sólidas para justificar tais revisões, o fato é que as instituições judiciais nem são "neutras", porque juízes são pessoas de "carne e osso" e possuem um sistema de valores e crenças com o qual buscam razões para fundamentar suas decisões, quando mais em casos difíceis. E não está claro se o poder de revisão torna a sociedade mais justa, pois não há resultados conclusivos para afirmar que produzem resultados benéficos socialmente; e porque, estruturalmente, não são aparadas com recursos para produzir informações técnicas em áreas como economia e saúde, em comparação com o Poder Executivo, que detém órgãos de inteligência com pessoal especializado tecnicamente nesses assuntos delicados da sociedade.

Enfim, é possível supor que o risco de erro judicial é muito mais problemático que o executivo, muito mais em crises e emergências. Ainda que o Ministro tente evitar danos à vida e à saúde das pessoas, o controle judicial sempre ocorre depois do fato, de modo que, quando se submete a ação política do Executivo ao escrutínio judicial, espera-se um tempo que talvez possa ser fatal aos direitos abrigados no processo, mormente, se a fundamentação da decisão judicial for levada a sério. No caso, o risco de erro na avaliação foi potencializado pela tese aparentemente inofensiva do Ministro Relator, assim como o risco de abuso de poder, mas do lado da mesa onde está o Poder Judiciário, cujos membros agora possuem outro precedente vago para responsabilizar os agentes públicos do Executivo.

\section{CONCLUSÃO}

De modo geral, é possível inferir que, independentemente das melhores intenções dos juízes, tanto em condições de normalidade institucional e, muito mais, em condições e circunstâncias como de crises e emergências, em que os tomadores de decisões estão sob condições de incertezas massivas, e tendo por objeto decisões administrativas que envolvem conceitos indeterminados e expressões abstratas, é imperativo que os juízes exerçam apenas um controle fino da constitucionalidade ou racionalidade constitucional dos atos controlados. Essa perspectiva leva em conta a falibilidade dos juízes e os possíveis efeitos perversos das decisões judiciais, deixando os buracos negros, e os "acordos teóricos incompletos", a cargo da discrição dos Poderes eleitos.

Se, de um lado, nem sempre o Executivo pode ser realmente controlado por mecanismos legais de maneira eficaz, de outro, sempre poderá ser restringido por mecanismos de constrangimento da política, como as eleições e a opinião pública, sobremaneira, pelas primeiras, nas quais o voto popular é o mais valioso artigo para, de fato, mostrar qual instituição pode assumir a frente da "guarda" da Constituição nas democracias contemporâneas.

\section{REFERÊNCIAS}

ALEXY, R. Teoria dos Direitos Fundamentais. 2ed. São Paulo: Malheiros. 2012.

BARROSO, L. R. A constitucionalização do direito e suas repercussões no âmbito administrativo. 2012. In: ARAGÃO, A.S.; NETO, F.A.M. (orgs.). Direito Administrativo e seus novos paradigmas. Belo Horizonte: Editora Fórum, 2012.

BARROSO, L. R. A razão sem o voto: o Supremo Tribunal Federal e o governo da maioria. In: VIEIRA, O.V.; GLEZER, R. (coord.). A razão e o voto: diálogos constitucionais com Luís Roberto Barroso. Rio de Janeiro: Fundação Getúlio Vargas, 2017. 
BIGONHA, A. C. P. MOREIRA, L. (coord.). Limites do Controle de Constitucionalidade. Rio de Janeiro: Lumen Juris, 2009.

BINEMBOJM, G. Uma teoria do Direito Administrativo: Direitos Fundamentais, Democracia e Constitucionalização. 2. ed. Rio de Janeiro: Renovar, 2008.

BÖCKENFÖRD, E-W. Constitutional and Political Theory. Selected Writings. Inglaterra: Oxford University Press, 2017.

https://doi.org/10.1093/acprof:oso/9780198714 965.001.0001

BRASIL. Congresso Nacional. Lei no 13.979, de 6 de fevereiro de 2020. dispõe sobre as medidas para enfrentamento da emergência de saúde pública de importância internacional decorrente do coronavírus responsável pelo surto de 2019. Diário Oficial da União, Brasília, DF, 7 fev. 2020.a Edição 27. Seção 1, Pág. 1. Disponível em: https://www.in.gov.br/en/web/dou/-/lei-n13.979-de-6-de-fevereiro-de-2020-242078735.

Acesso em: 15 out. 2020.

BRASIL. Presidência da República. Medida Provisória no 966 de 13 de maio de 2020. Dispõe sobre a responsabilização de agentes públicos por ação e omissão em atos relacionados com a pandemia da covid-19. Diário Oficial da União, Brasília, DF, 15 mai. 2020.b Edição 14. Seção 1. Página $6 . \quad$ Disponível em: http://www.planalto.gov.br/ccivil 03/ Ato20192022/2020/Mpv/mpv966.htm. Acesso em: 15 out. 2020.

BRASIL. SUPREMO TRIBUNAL FEDERAL. AÇÃO DIRETA DE INCONSTITUCIONALIDADE 6421 DF 0092667-18.2020.1.00.0000. Relator: Ministro Luís Roberto Barroso, 2020.c.

DYZENHAUS, D. The Constitucion of Law: Legality in a Time of Emergency. Cambridge: Univerity Press, 2006.

https://doi.org/10.1017/CBO9780511618246.

DWORKIN, R. Levando os direitos a sério. São Paulo: Martins Fontes, 2002.

DWORKIN, R. O Direito de Liberdade: a leitura moral da Constituição americana. São Paulo: Martins Fontes, 2006.
DWORKIN, R. 0 Império do Direito. 3. ed. São Paulo: Martins Fontes, 2014.

FREITAS, J. O Controle dos Atos Administrativos e os princípios fundamentais. São Paulo: Malheiros, 2015.

LARENZ, K. Metodologia da ciência do direito. 8ed. Lisboa: Fundação Calouste Gulbelkian, 2019.

POSNER, E.; VERMEULE, A. Crisis Governance in the Administrative State: $9 / 11$ and the Financial Meltdown of 2008 (November 13, 2008). U of Chicago Law \& Economics, Olin Working Paper No. 442; U of Chicago, Public Law Working Paper No. 248; Harvard Public Law Working Paper No. 08-50; Harvard Law School Program on Risk Regulation Research Paper No. 09-04. Disponível em:

SSRN: https://ssrn.com/abstract=1301164 or http ://dx.doi.org/10.2139/ssrn.130116.

POSNER, E.; VERMEULE, A. The Executive Unbound after the Madisonian republic. New York: Oxford University Press, 2010.

SCHMITT, C. O guardião da Constituição. Belo Horizonte: Del Rey. 2007

SCHMITT, C. Teoria de la Constituición. Verfassungslebre. Madrid: Alianza Editorial. 1996.

STRECK, Lênio L; TRINDADE, André K. Garantismo, hermenêutica e (neo)constitucionalismo: um debate com Luigi Ferrajoli. Porto Alegre: Livraria do Advogado. 2012.

SUNSTEIN, C.; VERMEULE, A. Interpretation and Institutions. Chicago, John M. Olin Law \& Economis Working Paper. n. 156. Public Law and Legal Theory Working paper n. 28. 2002 55p.

RAMOS, E. S. Ativismo Judicial: parâmetros dogmáticos. 2. ed. São Paulo: Saraiva, 2015.

VERMEULE, A. Law's Abnegation: From Law's Empire to the Administrative State. Massashussetts: Harvard University Press, 2016.

VERMEULE, A. The Constitution of Risk. New York: Cambridge University Press, 2014. 